\title{
The Neurovegetative Complaints Questionnaire in the Maastricht Aging Study: psychometric properties and normative data
}

Citation for published version (APA):

Hoogenhout, E., Van der Elst, W., De Groot, R., Van Boxtel, M., \& Jolles, J. (2010). The Neurovegetative Complaints Questionnaire in the Maastricht Aging Study: psychometric properties and normative data. Aging and Mental Health, 14(5), 613-623. https://doi.org/10.1080/13607861003587297

DOI:

10.1080/13607861003587297

Document status and date:

Published: 01/07/2010

Document Version:

Peer reviewed version

\section{Document license:}

CC BY-NC-ND

Please check the document version of this publication:

- A submitted manuscript is the version of the article upon submission and before peer-review. There can be important differences between the submitted version and the official published version of record. People interested in the research are advised to contact the author for the final version of the publication, or visit the DOI to the publisher's website.

- The final author version and the galley proof are versions of the publication after peer review.

- The final published version features the final layout of the paper including the volume, issue and page numbers.

Link to publication

\section{General rights}

Copyright and moral rights for the publications made accessible in the public portal are retained by the authors and/or other copyright owners and it is a condition of accessing publications that users recognise and abide by the legal requirements associated with these rights.

- Users may download and print one copy of any publication from the public portal for the purpose of private study or research.

- You may not further distribute the material or use it for any profit-making activity or commercial gain

- You may freely distribute the URL identifying the publication in the public portal.

If the publication is distributed under the terms of Article 25fa of the Dutch Copyright Act, indicated by the "Taverne" license above, please follow below link for the End User Agreement:

https://www.ou.nl/taverne-agreement

Take down policy

If you believe that this document breaches copyright please contact us at:

pure-support@ou.nl

providing details and we will investigate your claim.

Downloaded from https://research.ou.nl/ on date: 26 Apr. 2023 
The Neurovegetative Complaints Questionnaire in the Maastricht Aging Study:

psychometric properties and normative data 


\begin{abstract}
Neurovegetative and somatic symptoms (such as headaches, heart palpitations, and dizziness) have a high prevalence. These symptoms are often indicative for "masked depression' or 'depression without sadness', especially in older adults. At present, no instrument exists that enables the assessment of these symptoms. The current study presents a questionnaire that assesses neurovegetative and somatic complaints, as well as reactive emotional complaints: the 'Neurovegetative Complaints Questionnaire' (NCQ). The factor structure, internal consistency, and validity of the NCQ were evaluated in a large sample of 1,105 healthy subjects aged 24-81 years from the Maastricht Aging Study. The effects of age, gender and educational level on the NCQ measures were established to provide demographically corrected normative data. Two constructs underlay the responses to the NCQ items, i.e., the Neurovegetative/Somatic and Reactive/Emotional complaints factors (eigenvalues were 4.63 and 1.65 respectively, $33.0 \%$ of the variance was explained, Pearson's $r$ between both factors equalled .448). Internal consistency of both scales was acceptable (i.e. Cronbach's $\alpha=$ .74 and .71 , respectively) and convergent validity was sufficient (Pearson's $r=1.387$ $.499 \mid$ ). Females and older participants were characterized by more Neurovegetative/ Somatic and Reactive/Emotional complaints compared to males and younger people. Demographically corrected regression-based norms were provided for use in research and clinical settings. The NCQ is a psychometrically sound questionnaire that is specifically aimed at assessing neurovegetative/somatic and reactive/emotional complaints, symptoms that often are indicative for a 'masked depression'.
\end{abstract}




\section{Introduction}

Depressive problems (i.e., major depression, minor depression, dysthymia, subsyndromal depression, or depressive symptoms) are common in both younger (Ohayon, 2007; Zung, Broadhead, \& Roth, 1993) and older adults (Beekman, Deeg, van Tilburg et al., 1995; Hybels \& Blazer, 2003; Ohayon, 2007; Zung et al., 1993). However, due to the atypical phenomenology of depression in the latter age group, depressive problems in older adults often remain unnoticed, and its prevalence may consequently be underestimated. This may be caused by the discrepancy between diagnostic criteria for depressive problems as described by the DSM-IV (APA, 1994) and the way in which older adults with depressive problems present themselves in primary care (Alexopoulos et al., 2002; Christensen et al., 1999; Gallo \& Rabins, 1999; Hybels \& Blazer, 2003; Lyness, King, Cox, Yoediono, \& Caine, 1999).

According to Gallo and Rabins (1999), older adults with depressive problems often present themselves with somatic complaints for which a medical etiology cannot be found. Others report somatic complaints that are atypical or disproportionate to their medical illness. In fact, these people tend to report more somatic and neurovegetative symptoms (symptoms associated with suboptimal functioning of the autonomic nervous system, like sleeping problems, fatigue, and lack of energy (Venes, Thomas, \& Wilbur Taber, 2001)), rather than affective symptoms (Christensen et al., 1999; Gallo, Rabins, \& Anthony, 1999; Oxman, Barrett, Sengupta, \& Williams, 2000). This condition has previously been described as "masked depression" (Collins \& Abeles, 1996; Neskes \& Jarvik, 1987; Weiss, Nagel, \& Aronson, 1986) or "depression without sadness" (Alexopoulos et al., 2002; Gallo \& Rabins, 1999), a 'diagnosis' for which a golden standard or DSM-classification currently is lacking. Thus, although somatic and neurovegetative complaints frequently result from physical illness, they may also mask underlying depressive problems in older adults. This issue is of great importance for clinicians and researchers who work with older adults, because depressive problems are often related to impaired functional status (Cui, Lyness, Tang, Tu, \& Conwell, 2008; Gallo, Rebok, Tennsted, Wadley, \& Horgas, 2003; Oxman et al., 2000), increased subjective cognitive complaints (Collins \& Abeles, 1996; Dux et al., 2008; Mol, Ruiter, Verhey, Dijkstra, \& Jolles, 2008) and lowered cognitive performance (Bierman, Comijs, Jonker, \& Beekman, 2005; Den Hartog, Derix, Van Bemmel, Kremer, \& Jolles, 2003; Dux et al., 2008; Gallo et al., 2003), amongst others.

It is thus important to objectify these neurovegetative and somatic complaints in older persons (Alexopoulos et al., 2002; Collins \& Abeles, 1996; Gallo \& Rabins, 1999; Oxman et 
al., 2000). The Neurovegetative Complaints Questionnaire (NCQ) has been especially developed to measure neurovegetative and somatic as well as reactive emotional complaints. It has been shown a useful instrument in several specific populations, like brain injured adults (Bohnen, Jolles, Twijnstra, Mellink, \& Wijnen, 1995; Bohnen, Twijnstra, \& Jolles, 1992) and postmenopausal women (Hogervorst, Boshuisen, Riedel, Willeken, \& Jolles, 1999). Bohnen and colleagues (1995) showed that the NCQ was a valid instrument to distinguish several patterns of complaints in subgroups of patients with traumatic brain injury. In the study of Hogervorst and colleagues (1999), the NCQ was used to detect differences in subjective feelings of wellbeing between postmenopausal women who were offered hormone replacement therapy, and a non-treated group. However, until now, the psychometric properties of the NCQ have not been established in a general population sample.

The aims of the present study were therefore to investigate the factor structure, reliability (i.e., internal consistency) and validity of the NCQ in a general population sample. For that purpose, data of the Maastricht Aging Study, a large and unique community based study involving healthy adults aged 24 to 81 years, were used. Furthermore, the association between the NCQ scale scores and age, gender, and educational level was investigated, and normative data for its use in clinical and research settings were provided.

\section{Methods}

\section{Participants}

Data from the Maastricht Aging Study (MAAS) (Jolles, Houx, van Boxtel, \& Ponds, 1995), a prospective study into the determinants of cognitive aging, were used. Baseline measurements were conducted between 1993 and 1996. Participants were recruited from a regional registration network of general practitioners (Metsemakers, Hoppener, Knottnerus, Kocken, \& Limonard, 1992). Participants with a medical condition that could interfere with normal cognitive functioning were excluded (i.e., overt cerebrovascular disease, chronic neurological pathology, mental retardation, psychopathology, or chronic psychotropic drug use). Data were collected in 1,823 individuals. Participants were stratified for three demographic variables that are known to affect cognitive functioning, namely age (ranging from $25 \pm 1$ up to $80 \pm 1$ years), gender, and general ability (two levels, based on the professional achievement level). All participants filled in several questionnaires and were neuropsychologically tested. The Mini-Mental State Examination (MMSE) (Folstein, Folstein, \& McHugh, 1975) was administered to participants aged 50 years and older. The 
medical ethics committee of the Maastricht University Medical Centre approved the study. More details on the design and rationale of the Maastricht Aging Study were described elsewhere (Jolles et al., 1995).

In total, $N=1,325$ participants filled in the NCQ. The Mini-Mental State Examination (MMSE) scores of $n=19$ participants were below 24. The data of these people were not used in the present study because they were considered to be at risk of dementia (Folstein et al., 1975). In the remaining group, $n=191$ participants had one or more missing values in the NCQ. A total number of $N=1,105$ participants answered all questions and were included in the current study. Participants who did not respond to all questions were older, lower educated, and more often female $(p<.001)$. The SF-36, which was used to assess mental and physical wellbeing (Ware, Kosinski, \& Keller, 1994; Ware \& Sherbourne, 1992), was administered to 742 participants of the remaining group. Table 1 shows the distribution of gender and educational level of the total sample and per age group in detail.

Table 1 Distribution of gender and educational level per age group

\begin{tabular}{|c|c|c|c|c|c|c|c|c|c|c|c|c|c|}
\hline Age group & $\begin{array}{c}25 \\
\pm 1\end{array}$ & $\begin{array}{c}30 \\
\pm 1\end{array}$ & $\begin{array}{c}35 \\
\pm 1\end{array}$ & $\begin{array}{c}40 \\
\pm 1\end{array}$ & $\begin{array}{c}45 \\
\pm 1\end{array}$ & $\begin{array}{c}50 \\
\pm 1\end{array}$ & $\begin{array}{r}55 \\
\pm 1\end{array}$ & $\begin{array}{c}60 \\
\pm 1\end{array}$ & $\begin{array}{c}65 \\
\pm 1\end{array}$ & $\begin{array}{c}70 \\
\pm 1\end{array}$ & $\begin{array}{c}75 \\
\pm 1\end{array}$ & $>79$ & Total \\
\hline $\mathrm{N}$ & 106 & 106 & 111 & 106 & 107 & 104 & 98 & 93 & 82 & 99 & 75 & 18 & 1,105 \\
\hline \multicolumn{14}{|l|}{ Gender } \\
\hline$\%$ women & 47.2 & 45.3 & 50.5 & 48.1 & 51.4 & 48.1 & 46.9 & 41.9 & 40.2 & 46.5 & 42.7 & 50.0 & 46.5 \\
\hline$\%$ men & 52.8 & 54.7 & 50.5 & 51.9 & 48.6 & 51.9 & 53.1 & 58.1 & 59.8 & 53.5 & 57.3 & 50.0 & 53.5 \\
\hline \multicolumn{14}{|l|}{ Education } \\
\hline$\%$ low & 11.3 & 15.1 & 18.0 & 20.8 & 33.6 & 29.8 & 51.0 & 43.0 & 52.4 & 56.6 & 42.7 & 50.0 & 33.2 \\
\hline$\%$ medium & 46.2 & 54.7 & 51.4 & 45.2 & 40.2 & 45.2 & 30.6 & 44.1 & 34.1 & 29.3 & 38.7 & 16.7 & 41.8 \\
\hline$\%$ high & 42.5 & 30.2 & 30.6 & 34.0 & 26.2 & 25.0 & 18.4 & 12.9 & 13.3 & 14.1 & 18.6 & 33.3 & 25.0 \\
\hline
\end{tabular}

The ethnic background of all participants was Caucasian, and all were native Dutch speakers. Mean IQ score, as estimated with a shortened version of the Groningen Intelligence Test (Luteijn \& van der Ploeg, 1983), was 114.5 (SD = 12.6). Level of education (LE) was measured by classifying the formal schooling of participants in one of three groups, those with at most primary education (LE low), those with at most junior vocational training or high school (LE average) and those with at most senior vocational or academic training (LE high). This LE system is often used in The Netherlands (De Bie, 1987) and is comparable with the International Standard Classification of Education (UNESCO, 1976). LE low, LE average and LE high correspond with an average of 8.72, 11.54 and 15.34 years of full-time education in the sample $(S D=1.82,2.57$, and 3.29), respectively. 


\section{Neurovegetative Complaints Questionnaire}

The Neurovegetative Complaints Questionnaire (NCQ) was originally developed to measure neurovegetative and somatic as well as emotional complaints in post-concussive patients (Bohnen et al., 1992). The original questionnaire consisted of 28 items concerning headaches, problems with falling asleep, restlessness, chest pain, indigestion, slowness of working, sensitivity to light, effort, flushing, concentration, dyspnoea, preference to be left alone, tiredness, fainting, heart palpitations, noise, difficulty with doing two tasks simultaneously, preference to work at ones own pace, dizziness, depression, wet hands, crying spells, libido, irritability, lack of initiative, awakening at night, defeatism, and not being appreciated by others. Participants had to indicate the frequency of occurrence of these symptoms on a 4point Likert scale ( 1 = "no, never"; 2 = "yes, sometimes"; 3 = "yes, regularly", and 4 = "yes, often"). Higher scores indicated more complaints.

\section{Other measures}

The Depression and Anxiety subscales of the Symptom Checklist-90 (SCL-90; Arrindell \& Ettema 1986), a self-report measure of psychopathology, were administered to evaluate the convergent validity of the NCQ. The SCL-90 Depression subscale consisted of 16 items that assess both affective complaints (such as lack of interest) and somatic/neurovegetative symptoms of depression (such as lack of libido). The Anxiety subscale consisted of 10 items that assess affective and somatic symptoms that are related to high levels of anxiety (such as heart palpitations and restlessness). All SCL-90 items were rated on a 5-point Likert scale with a score range between 1 and 5. Higher scores indicated more symptoms (Arrindell \& Ettema, 1986; Derogatis, 1977).

The Medical Outcomes Study 36-item Short-Form Health Survey (SF-36) (Ware \& Sherbourne, 1992) is a self-report generic health measure that contained 36 items. Nine subscales can be derived from this questionnaire, respectively (1) physical functioning, (2) social functioning, (3) role limitations (physical problem), (4) role limitations (emotional problem), (5) mental health, (6) vitality, (7) pain, (8) general health, and (9) health change. From these subscales, two main factors can be composed, namely the Mental and the Physical wellbeing composite scores (Ware et al., 1995; Ware et al., 1994). 


\section{Statistical Analyses}

Exploratory Principal Component Analyses (PCAs) with an oblique rotation (Promax), which allows the factors to correlate, were conducted on the individual item scores of the NCQ to assess its dimensionality and to identify meaningful underlying constructs. The screeplot was used to determine the number of components to be retained (Cattell, 1966). Items with factor loadings of at least 0.40 were considered relevant. Items that loaded on two or more factors, or on no factor at all, were removed one at a time. Scale scores were established by adding up the raw item scores of the items that loaded at least $\geq .40$ on the components at hand.

Internal consistency (which is a lower bound of reliability) of the scales was assessed by calculating Cronbach's alpha coefficients. Pearson's correlations were calculated between the obtained scale scores of the NCQ and scores on the subscales Depression and Anxiety of the SCL-90, and the Mental and Physical composite scores of the SF-36 in order to test convergent validity. Both the SCL-90 subscale scores as well as the Mental and Physical composite scores of the SF-36 were expected to correlate high with the Neurovegetative Complaints scale scores.

Normative analyses were performed by regressing the established scale scores of the NCQ on age, age $^{2}$, gender, educational level (dummy coded into three levels with LE average as the reference category) and all two-way interactions between these predictors (the 'full models'). In order to avoid multicollinearity, age was centered (age = calendar age - 50) before quadratic terms and interactions were calculated. Non-significant predictors $(p>.01)$ were excluded from the model, but no predictor was removed as long as it was also included in a higher order term in the model (Aiken \& West, 1991). The assumptions of regression analysis were tested for each model. Homoscedasticity was evaluated by means of scatter plots of the residuals against the predicted values, and by grouping participants into quartiles of the predicted scores and applying the Levene test. Normal distribution of the residuals was investigated by visual inspection of the histograms of the residuals, and by conducting Kolmogorov-Smirnov tests on the residuals. The occurrence of multicollinearity was checked by calculating the Variance Inflation Factors (VIFs), which should not exceed 10 (Belsley, Kuh, \& Welsch, 1980). Potential influential cases were identified by calculating Cook's distances. All analyses were conducted using SPSS 15.0 for Windows.

Normative data for the scale scores of the NCQ can be obtained by calculating standardized residuals. These standardized residuals are converted into percentiles by means of a standard normal distribution table with cumulative probabilities (if the model assumption of normality of the residuals was met), or by means of a table with the observed distribution 
of the standardized residuals with cumulative probabilities (if the residuals were not normally distributed in the normative sample) (for details on the normative method, see Van der Elst, Van Boxtel, Van Breukelen, \& Jolles, 2007).

\section{Results}

\section{Factor structure}

The results of the Principal Component Analyses are shown in Table 2. Of the initial 28 items, 9 items were excluded because they loaded high on both factors. The remaining 19 items of the NCQ loaded high $(>.40)$ on a single factor. The first factor was labelled as "Neurovegetative/Somatic complaints". Items that assess headaches, problems falling asleep, restlessness, chest pain, slowness of working, sensitivity to light, effort, concentration, dyspnoea, heart palpitations and dizziness loaded high on this factor. The second factor was labelled as "Reactive/Emotional complaints" and items concerning preference to be left alone, difficulty to endure noise, difficulty doing two simultaneous tasks, preference to work at own pace, irritability, lack of initiative, defeatism and appreciation by others loaded high on this factor. The raw item scores of items that loaded at least $\geq .40$ on these two factors were summated for use in the subsequent analyses. These scale scores are referred to as the Neurovegetative/Somatic complaints scale score (mean $\pm S D=17.60 \pm 4.374$; range 11-34 in the normative sample) and the Reactive/Emotional complaints scale score $(16.08 \pm 3.633$; range 8-31 in the normative sample). Higher scale scores indicate more complaints (i.e., worse functioning). Eigenvalues of the factors were 4.63 and 1.65, respectively. The two factors accounted for 33.0 percent of the variance in the data. Pearson's correlations indicated a medium relation $(r(1105)=.448, p<.01)$ between the Neurovegetative/Somatic complaints and Reactive/Emotional complaints scale scores. 
Table 2 Factor loadings obtained by Principal Component Analyses with Promax rotation in which two factors were extracted

\begin{tabular}{lcc}
\hline Item & Neurovegetative/Somatic & Reactive/Emotional \\
\hline Headaches & $\mathbf{. 4 1 1}$ & .026 \\
Problems with falling asleep & $\mathbf{. 4 3 1}$ & .062 \\
Restlessness & $\mathbf{. 6 9 0}$ & -.148 \\
Chest pain & $\mathbf{. 5 2 2}$ & -.019 \\
Slowness of working & $\mathbf{. 4 9 0}$ & .272 \\
Sensitivity to light & $\mathbf{. 6 1 5}$ & -.343 \\
Effort & $\mathbf{. 5 2 9}$ & .180 \\
Concentration & $\mathbf{. 6 2 4}$ & -.148 \\
Dyspnoea & $\mathbf{. 5 0 6}$ & .135 \\
Preference to be left alone & .004 & $\mathbf{. 5 9 7}$ \\
Heart palpitations & $\mathbf{. 5 3 4}$ & .056 \\
Noise & .129 & $\mathbf{. 4 7 2}$ \\
Difficulty doing two simultaneous tasks & .093 & $\mathbf{. 5 5 5}$ \\
Preference to work at own pace & -.325 & $\mathbf{6 6 3}$ \\
Dizziness &. $\mathbf{4 2 4}$ & .110 \\
Irritability & .127 & $\mathbf{6 1 9}$ \\
Lack of initiative & .218 & $\mathbf{. 4 9 3}$ \\
Defeatism & .254 & $\mathbf{. 4 6 5}$ \\
Not being appreciated by others & -.248 & $\mathbf{. 5 6 5}$ \\
Initial eigenvalue for each component & & \\
Percentage of variance accounted for & 4.63 & \\
Cronbach's alpha & 24.4 & \\
\hline & .74 & \\
& &
\end{tabular}

\section{Reliability and validity}

Internal consistency was examined by calculating Cronbach's alpha. The items of the Neurovegetative/Somatic complaints and Reactive/Emotional complaints scales had an acceptable internal consistency ( $\alpha=.74$ and .71 , respectively). These values are lower bounds on reliability, which means that at least 71-74 percent of the total within-test score variance for the Reactive/Emotional complaints and the Neurovegetative/Somatic complaints scale scores was due to true score variance rather than to item content heterogeneity or poor item quality.

Convergent validity was evaluated by calculating Pearson correlations between the Neurovegetative/Somatic complaints and the Reactive/Emotional complaints scale scores of the NCQ on the one hand, and the Depression and Anxiety subscale scores of the SCL-90, and the Physical and Mental composite scores of the SF-36 on the other hand. For the 
Neurovegetative/Somatic scale score, correlations showed medium effect sizes (Cohen, 1988) with the SCL-90-Depression score $(r(1080)=.434, p<.01)$, the SCL-Anxiety score $(r(1081)$ $=-.485, p<.01)$, and the SF-36-Mental composite score $(r(742)=-.436, p<.01)$, and a large effect size with the SF-36-Physical composite score $(r(742)=-.499, p<.01)$. For the Reactive/Emotional complaints scale score, correlations showed medium effect sizes with the SCL-90-Depression score $(r(1080)=.398, p<.01)$, the SCL-90-Anxiety score $(r(1081)=$ $.387, p<.01)$ and the SF-36-Mental component score $(r(742)=-.442, p<.01)$. The relation between the Reactive/Emotional complaints scale score and the SF-36-Physical component score was weaker but still significant $(r(742)=-.172, p<.01)$.

\section{Normative data}

The final regression models for the Neurovegetative/Somatic complaints and the Reactive/Emotional complaints scale scores are presented in Table 2. No influential cases were identified (maximum Cook's distance equalled .043) for either model, and no multicollinearity occurred (maximum VIF $=2.535$ ). Scatter plots of the residuals against the predicted scores suggested a trend to heteroscedasticity for the Neurovegetative/Somatic complaints score model, which was confirmed by the Levene test $(p<.01)$. This was taken into account by calculating the standard deviations of the residuals per quartile of the predicted scores. These $S D$ (residual)s equalled 3.36 for predicted Neurovegetative/Somatic scale scores below 16.05, 4.12 for predicted scores between 16.06 and 17.45, 3.88 for predicted scores between 17.46 and 19.15, and 4.50 for predicted scores higher than 19.16. Scatter plots and the Levene test suggested that the homoscedasticity assumption was met for the final model of the Reactive/Emotional scale score. The $S D$ (residual) to be used in the standardization of the Reactive/Emotional complaints scale scores equals 3.58. The histograms of the residuals of both the Neurovegetative/Somatic complaints and the Reactive/Emotional complaints scale scores suggested that the residuals were not normally distributed (which was confirmed by the Kolmogorov-Smirnov test, $Z=2.539, p<.001$ and $Z=1.828, p=.003$, respectively). This was taken into account by converting the standardized residuals into percentiles by means of the observed distribution of the standardized residuals (rather than by means of the standard normal distribution).

The final models showed that female participants reported more neurovegetative and somatic complaints (i.e., worse functioning) than their male counterparts. There was a significant age $\mathrm{x}$ educational level interaction, which suggested that the effect of educational level on Neurovegetative/Somatic complaints varied as a function of age. Reactive/Emotional 
complaints scale scores were affected by age and gender, i.e., older and female participants reported more reactive emotional complaints than younger and male participants (see Table $3)$.

Table 3 Final multiple linear regression models for the Neurovegetative/Somatic and the Reactive/Emotional complaints scale scores following a step-down hierarchical procedure.

\begin{tabular}{llrrrrr}
\hline Scale score & \multicolumn{1}{c}{ Variable } & \multicolumn{1}{c}{ B } & Std.Error B & \multicolumn{1}{c}{ T } & Standardized B & $\mathrm{R}^{2}$ \\
\hline Neurovegetative/Somatic & (constant) & 17.857 & .231 & $77.408^{* *}$ & .208 \\
& Age & .077 & .012 & $6.389^{* *}$ & -.131 \\
& Gender & -1.149 & .246 & $-4.670^{* *}$ & .237 \\
& LE Low & 2.199 & .297 & $7.413^{* *}$ & -.096 \\
& LE High & -.967 & .319 & $-3.030^{* *}$ & -.119 \\
& Age*LE Low & -.060 & .019 & $-3.140^{* *}$ & -.050 \\
Age*LE High & -.027 & .020 & -1.363 & .170 \\
& & & & & .137 \\
& (constant) & 16.533 & .158 & $104.542^{* *}$ & .111 \\
\end{tabular}

Note. The full model included age, age ${ }^{2}$, LE low, LE high, gender, and all 2-way interactions between these predictors. LE $=$ Level of education. Coding of the predictors: Age $=$ calendar age -50 ; Gender: male $=1$, female $=0$; LE Low: Low education $=1$, Average or High Education $=0$; LE High: High Education $=1$, Low or Average Education $=0$. ** $p<.01$

Normative tables are provided for the Neurovegetative/Somatic complaints scale score (see Appendix 1) and for the Reactive/Emotional complaints scale score (see Appendix 2). If an individual is not exactly $25,30, \ldots, 80$ years old, then that person's age should be rounded up to the closest age given in the normative tables. Interpretation of the raw scale scores is straightforward by means of the normative tables. For example, a 64 year old man with an average educational level had a score of 24 on the Neurovegetative/Somatic complaints scale score and a score of 10 on the Reactive/Emotional complaints scale score. His age is rounded up to the closest age given in the tables, i.e. 65 years. The normative tables indicate that a raw Neurovegetative/Somatic complaints scale score of 24 corresponds with a percentile between 1 and 5 (i.e., a lot of complaints) and a raw Reactive/Emotional complaints scale score of 10 corresponds with a percentile score between 90 and 95 (i.e., few complaints). 


\section{Discussion}

The NCQ was developed to measure neurovegetative and somatic as well as emotional complaints in adults. It has been proven a useful assessment tool in several clinical populations (Bohnen et al., 1995; Bohnen et al., 1992; Hogervorst et al., 1999), but until now its psychometric properties have not been evaluated in a general population sample. Neurovegetative and somatic symptoms may be a sign of "masked depression" (Collins \& Abeles, 1996; Neskes \& Jarvik, 1987; Weiss et al., 1986) or "depression without sadness" (Alexopoulos et al., 2002; Gallo \& Rabins, 1999). In other words, older adults may present with alternative clinical clues to depression (Gallo \& Rabins, 1999). Furthermore, neurovegetative and somatic complaints are common in other target groups too, like chronic pain patients (Geisser, Roth, \& Robinson, 1997; Wesley, Gatchel, Polatin, Kinney, \& Mayer, 1991) and brain injured individuals (Bohnen et al., 1995; Bohnen et al., 1992). It is, therefore, important to develop new instruments that measure these neurovegetative and somatic symptoms. In the current study, the factor structure, reliability and validity of the NCQ were investigated in a large population sample ( $N=1,105$ healthy adults aged $24-81$ years), and normative data were provided.

PCAs using an oblique rotation reduced the number of items from 28 to 19 items that loaded on two factors. The primary factor assesses neurovegetative and somatic symptoms (like heart palpitations and headaches), whereas the secondary factor reflects reactive emotional symptoms (like irritability and lack of initiative). Both the Neurovegetative/Somatic complaints scale and the Reactive/Emotional complaints scale had acceptable levels of internal consistency $(>.70)$, indicating that their items measure the same underlying constructs. Convergent validity was examined by correlating both scale scores to established measures that assess comparable constructs, i.e., the SCL-90 Depression and Anxiety subscales (Arrindell \& Ettema, 1986; Derogatis, 1977), and the Mental and Physical component scores of the SF-36 (Ware et al., 1994). Significant correlations were found between both scale scores of the NCQ and these other measures. All correlations showed medium to large effect sizes, except for the correlation between Reactive/Emotional symptoms and the Physical component of the SF-36, which showed a small effect size. This pattern of correlations was expected, because items of the SF-36 Physical component primarily reflect physical wellbeing (Ware et al., 1994), whereas items of the Reactive/Emotional complaints scale of the NCQ resemble more affective and mental aspects of wellbeing. In sum, these results point to a satisfactory convergent validity of the 
Neurovegetative/Somatic complaints and the Reactive/Emotional complaints scales of the NCQ.

Normative data for both scale scores were obtained with multiple regression analyses following a step-down hierarchical procedure. Normative tables that take the relevant demographical variables for each scale score into account were established (see Tables 3 and 4). The final models showed that older and female participants reported more neurovegetative/somatic and reactive/emotional complaints than their younger and male counterparts. This is in accordance with other studies. For example, more severe self-reported (somatic and affective) depressive symptoms were associated to higher age and being female (Beekman, Kriegsman, Deeg, \& van Tilburg, 1995; Zung et al., 1993). Looking at individual items of self-reported measures of depression, Christensen et al. (1999) established a direct effect of age on both somatic as well as psychological symptoms of depression. However, being female was only significantly associated to reporting somatic symptoms, but not to reporting psychological symptoms (Christensen et al., 1999). In our study, neurovegetative and somatic complaints were affected by a significant age $\mathrm{x}$ educational level interaction, which suggested that the differences in reported somatic symptoms of high, moderate and low educated people decreased as a function of age. Reactive emotional complaints were not affected by educational level. Previous findings on this topic are inconsistent. Some studies found no association between educational level and (somatic and affective) symptoms of depression (Beekman, Deeg, Smit, \& van Tilburg, 1995; Beekman, Kriegsman et al., 1995), whereas others found a significant negative association (Christensen et al., 1999; Zung et al., 1993). However, to our knowledge, no previous study has investigated the association between educational level and neurovegetative/somatic complaints or emotional complaints separately.

Existing self-report measures, like the BDI (Beck, Steer, \& Garbin, 1988) and the CES-D (Radloff, 1977), contain several somatic and affective items that fit the DSM-IV criteria for depression (APA, 1994). Other well established tools are the PHQ, an established measure for making DSM-IV- criteria based diagnosis of mental disorders in primary care (Spitzer, Kroenke, \& Williams, 1999), and the shortened PHQ-15 (for somatic symptom severity) (Kroenke, Spitzer, \& Williams, 2002) and the PHQ-9 (for depressive symptom severity) (Kroenke, Spitzer, \& Williams, 2001). However, the way in which older adults with depressive problems present themselves in primary care may differ from these DSM-IVbased criteria. They often report mainly neurovegetative and somatic complaints, like headaches, heart palpitations, or dizziness, instead of affective and emotional complaints. 
Although these neurovegetative and somatic complaints frequently result from physical illness, they are in some cases atypical or disproportionate to medical illness, and may rather mask underlying depressive problems. The use of DSM-IV-criteria based instruments may lead to an underestimation of mental health problems and depressive symptoms (Alexopoulos et al., 2002; Collins \& Abeles, 1996; Gallo \& Rabins, 1999; Klapow et al., 2002; Neskes \& Jarvik, 1987). Thus when considering wellbeing in older adults, it is of high importance to pay special attention to these neurovegetative and somatic complaints.

From the current study it can be concluded that the NCQ is a psychometrically sound questionnaire for which normative data are available. It may provide a useful tool in clinical as well as in research settings to assess neurovegetative and somatic complaints, and reactive emotional complaints. However, normative data are based on a Dutch sample and need further validation in an English speaking population. Furthermore, additional research is needed to further investigate aspects of construct and criterion validity (Drenth \& Sijtsma, 1990) of the NCQ. Moreover, it is necessary to investigate if it is a better tool to screen for masked depression or depression without sadness than DSM-IV-criteria based instruments like the BDI, PHQ, or CES-D. Unfortunately, a gold standard and official diagnostic criteria for this condition are lacking until now. The NCQ should thus be used in addition to existing instruments. Finally, the NCQ could be investigated in other populations in which neurovegetative and somatic complaints may be relevant, like chronic pain patients (Geisser et al., 1997; Wesley et al., 1991) or adults with depressive symptoms (Levitan, Lesage, Parikh, Goering, \& Kennedy, 1997; Nierenberg, Pava, Clancy, Rosenbaum, \& Fava, 1996; Rapaport et al., 2002), in order to study its clinical usefulness. 


\section{References}

Aiken, L. S., \& West, S. G. (1991). Multiple regression: Testing and interpreting interactions. Newbury Park, California: Sage.

Alexopoulos, G. S., Borson, S., Cuthbert, B. N., Devanand, D. P., Mulsant, B. H., Olin, J. T., \& Oslin, D. W. (2002). Assessment of late life depression. Biological Psychiatry, 52, 164-174.

APA (1994). Diagnostic and Statistical Manual of Mental Disorders: DSM-IV. Washington: American Psychiatric Association.

Arrindell, W. A., \& Ettema, J. H. M. (1986). SCL-90: Manual for a multi-dimensional indicator of psychopathology [Handleiding bij een multidimensionele psychopathologie-indicator]. Lisse, the Netherlands: Swets \& Zeitlinger BV.

Beck, A. T., Steer, R. A., \& Garbin, M. G. (1988). Psychometric properties of the Beck Depression Inventory: twenty-five years of evaluation. Clinical Psychology Review, 8, 77-100.

Beekman, A. T., Deeg, D. J., Smit, J. H., \& van Tilburg, W. (1995). Predicting the course of depression in the older population: results from a community-based study in The Netherlands. Journal of Affective Disorders, 34, 41-49.

Beekman, A. T., Deeg, D. J., van Tilburg, T., Smit, J. H., Hooijer, C., \& van Tilburg, W. (1995). Major and minor depression in later life: a study of prevalence and risk factors. Journal of Affective Disorders, 36, 65-75.

Beekman, A. T., Kriegsman, D. M., Deeg, D. J., \& van Tilburg, W. (1995). The association of physical health and depressive symptoms in the older population: age and sex differences. Social Psychiatry and Psychiatric Epidemiology, 30, 32-38.

Belsley, D. A., Kuh, E., \& Welsch, R. E. (1980). Regression diagnostics: Identifying influential data and sources of collinearity. New York: Wiley.

Bierman, E. J., Comijs, H. C., Jonker, C., \& Beekman, A. T. (2005). Effects of anxiety versus depression on cognition in later life. American Journal of Geriatric Psychiatry, 13, 686-693.

Bohnen, N. I., Jolles, J., Twijnstra, A., Mellink, R., \& Wijnen, G. (1995). Late neurobehavioural symptoms after mild head injury. Brain Injury, 9, 27-33.

Bohnen, N. I., Twijnstra, A., \& Jolles, J. (1992). Post-traumatic and emotional symptoms in different subgroups of patients with mild head injury. Brain Injury, 6, 481-487.

Cattell, R. B. (1966). The scree test for the number of factors. Multivariate Behavioral Research, 1, 629-637.

Christensen, H., Jorm, A. F., Mackinnon, A. J., Korten, A. E., Jacomb, P. A., Henderson, A. S., \& Rodgers, B. (1999). Age differences in depression and anxiety symptoms: a structural equation modelling analysis of data from a general population sample. Psychological Medicine, 29, 325-339.

Cohen, A. L. (1988). Statistical power analysis for the behavioral sciences. Hillsdale, NJ: Erlbaum

Collins, M. W., \& Abeles, N. (1996). Subjective memory complaints and depression in the able elderly. Clinical Gerontologist, 16, 29-54.

Cui, X., Lyness, J. M., Tang, W., Tu, X., \& Conwell, Y. (2008). Outcomes and predictors of late-life depression trajectories in older primary care patients. American Journal of Geriatric Psychiatry, 416, 406-415.

De Bie, S. E. (1987). Toward a standardization of questions concerning demographic variables in population studies [Standaardvragen 1987 - Voorstellen voor 
uniformering van vraagstellingen naar achtergrondkenmkernen en interviews]. Leiden, The Netherlands: Leiden University Press.

Den Hartog, H. M., Derix, M. M., Van Bemmel, A. L., Kremer, B., \& Jolles, J. (2003). Cognitive functioning in young and middle-aged unmedicated out-patients with major depression: testing the effort and cognitive speed hypotheses. Psychological Medicine, 33, 1443-1451.

Derogatis, L. R. (1977). SCL-90: Administration, scoring and procedures manual-i for the $R$ (evised) version. Baltimore MD: John Hopkins School of Medicine, Clinical Psychometrics Research Unit.

Drenth, P. J., \& Sijtsma, K. (1990). Theory of testing: Introduction to the theory of psychological testing and its application [Testtheorie: Inleiding in de theorie van de psychologische test en zijn toepassingen]. Houten/Diegem: Bohn Stafleu Van Loghum.

Dux, M. C., Woodard, J. L., Calamari, J. E., Messina, M., Arora, S., Chik, H., \& Pontarelli, N. (2008). The moderating role of negative affect on objective verbal memory performance and subjective memory complaints in healthy older adults. Journal of the International Neuropsychological Society, 14, 327-336.

Folstein, M. F., Folstein, S. E., \& McHugh, P. R. (1975). "Mini-mental state". A practical method for grading the cognitive state of patients for the clinician. Journal of Psychiatric Research, 12, 189-198.

Gallo, J. J., \& Rabins, P. V. (1999). Depression without sadness: alternative presentations of depression in late life. American Family Physician, 60, 820-826.

Gallo, J. J., Rabins, P. V., \& Anthony, J. C. (1999). Sadness in older persons: 13-year followup of a community sample in Baltimore, Maryland. Psychological Medicine, 29, 341350.

Gallo, J. J., Rebok, G. W., Tennsted, S., Wadley, V. G., \& Horgas, A. (2003). Linking depressive symptoms and functional disability in late life. Aging and Mental Health, 7, 469-480.

Geisser, M. E., Roth, R. S., \& Robinson, M. E. (1997). Assessing depression among persons with chronic pain using the Center for Epidemiological Studies-Depression Scale and the Beck Depression Inventory: a comparative analysis. The Clinical Journal of Pain, 13, 163-170.

Hogervorst, E., Boshuisen, M., Riedel, W., Willeken, C., \& Jolles, J. (1999). 1998 Curt P. Richter Award. The effect of hormone replacement therapy on cognitive function in elderly women. Psychoneuroendocrinology, 24, 43-68.

Hybels, C. F., \& Blazer, D. G. (2003). Epidemiology of late-life mental disorders. Clinics in Geriatric Medicine, 19, 663-696.

Jolles, J., Houx, P. J., van Boxtel, M. P., \& Ponds, R. W. (1995). Maastricht Aging Study: determinants of cognitive aging. Maastricht: Neuropsych Publishers.

Klapow, J., Kroenke, K., Horton, T., Schmidt, S., Spitzer, R., \& Williams, J. B. (2002). Psychological disorders and distress in older primary care patients: a comparison of older and younger samples. Psychosomatic Medicine, 64, 635-643.

Kroenke, K., Spitzer, R. L., \& Williams, J. B. (2001). The PHQ-9: validity of a brief depression severity measure. Journal of General Internal Medicine, 16, 606-613.

Kroenke, K., Spitzer, R. L., \& Williams, J. B. (2002). The PHQ-15: validity of a new measure for evaluating the severity of somatic symptoms. Psychosomatic Medicine, 64, 258-266.

Levitan, R. D., Lesage, A., Parikh, S. V., Goering, P., \& Kennedy, S. H. (1997). Reversed neurovegetative symptoms of depression: a community study of Ontario. American Journal of Psychiatry, 154, 934-940. 
Luteijn, F., \& van der Ploeg, F. A. E. (1983). Manual Groningen Intelligence Test [Handleiding Groninger Intelligentietest (GIT)]. Lisse: Swets \& Zeitlinger.

Lyness, J. M., King, D. A., Cox, C., Yoediono, Z., \& Caine, E. D. (1999). The importance of subsyndromal depression in older primary care patients: prevalence and associated functional disability. Journal of the American Geriatrics Society, 47, 647-652.

Metsemakers, J. F., Hoppener, P., Knottnerus, J. A., Kocken, R. J., \& Limonard, C. B. (1992). Computerized health information in The Netherlands: a registration network of family practices. British Journal of General Practice, 42, 102-106.

Mol, M. E., Ruiter, R. A., Verhey, F. R., Dijkstra, J., \& Jolles, J. (2008). A study into the psychosocial determinants of perceived forgetfulness: implications for future interventions. Aging and Mental Health, 12, 167-176.

Neskes, R. E., \& Jarvik, L. F. (1987). Affective disorders in the elderly. Annual Review of Medicine, 38, 445-456.

Nierenberg, A. A., Pava, J. A., Clancy, K., Rosenbaum, J. F., \& Fava, M. (1996). Are neurovegetative symptoms stable in relapsing or recurrent atypical depressive episodes? Biological Psychiatry, 40, 691-696.

Ohayon, M. M. (2007). Epidemiology of depression and its treatment in the general population. Journal of Psychiatric Research, 41, 207-213.

Oxman, T. E., Barrett, J. E., Sengupta, A., \& Williams, J. W., Jr. (2000). The relationship of aging and dysthymia in primary care. American Journal of Geriatric Psychiatry, 8, 318-326.

Radloff, L. (1977). The CES-D scale: a self-report depression scale for research in the general population. Journal of Applied Psychological Measurement, 1, 385-401.

Rapaport, M. H., Judd, L. L., Schettler, P. J., Yonkers, K. A., Thase, M. E., Kupfer, D. J., Frank, E., Plewes, J. M., Tollefson, G. D., \& Rush, A. J. (2002). A descriptive analysis of minor depression. American Journal of Psychiatry, 159, 637-643.

Spitzer, R. L., Kroenke, K., \& Williams, J. B. (1999). Validation and utility of a self-report version of PRIME-MD: the PHQ primary care study. Primary Care Evaluation of Mental Disorders. Patient Health Questionnaire. Journal of the American Medical Association, 282, 1737-1744.

UNESCO (1976). International Standard Classification of Education (ISCED). Paris: United Nations Educational, Scientific and Cultural Organisation.

Van der Elst, W., Van Boxtel, M. P., Van Breukelen, G. J., \& Jolles, J. (2007). Assessment of information processing in working memory in applied settings: the paper and pencil memory scanning test. Psychological Medicine, 37, 1335-1344.

Venes, D., Thomas, C. L., \& Wilbur Taber, C. (2001). Taber's cyclopedic medical dictionary: F.A. Davis Company.

Ware, J. E., Kosinski, M., Bayliss, M. S., McHorney, C. A., Rogers, W. H., \& Raczek, A. (1995). Comparison of methods for the scoring and statistical analysis of SF-36 health profile and summary measures: summary of results from the Medical Outcomes Study. Medical Care, 33, AS264-279.

Ware, J. E., Kosinski, M., \& Keller, S. D. (1994). SF-36 Physical and Mental summary scales: a user's manual. Boston, MA: The Health Institute.

Ware, J. E., \& Sherbourne, C. D. (1992). The MOS 36-item short-form healt survey (SF-36): I. conceptual framework and item selection. Medical Care, 30, 473-483.

Weiss, I. K., Nagel, C. L., \& Aronson, M. K. (1986). Applicability of depression scales to the old old person. Journal of the American Geriatrics Society, 34, 215-218.

Wesley, A. L., Gatchel, R. J., Polatin, P. B., Kinney, R. K., \& Mayer, T. G. (1991). Differentiation between somatic and cognitive/affective components in commonly 
used measurements of depression in patients with chronic low-back pain. Let's not mix apples and oranges. Spine, 16, S213-S215.

Zung, W. W., Broadhead, W. E., \& Roth, M. E. (1993). Prevalence of depressive symptoms in primary care. The Journal of Family Practice, 37, 337-344. 